\title{
An evaluation of child health clinic services in Newcastle upon Tyne during 1972-1974
}

\author{
H. STEINER
}

From the University of Newcastle upon Tyne

SUMMARY The community child health clinics continued to provide an important and popular service for mothers with young children in Newcastle during 1972-74, supplementing the primary care services of general practitioners as only a minority of them had undertaken the preventive aspects of child care. Most of the work of the community clinics was done by health visitors and it consisted of advice, support, and reassurance about the everyday problems of children. Although an appreciable amount of the work of the community doctors was developmental screening (birthday checks) most mothers consulted them about relatively minor medical complaints-such as feeding difficulties, specific developmental problems, and immunisation. There was no attempt to do a birthday check on all the children in the city and those that were done revealed few significant undetected abnormalities because most of the children had already attended clinics. In a poor area of the city, family and social problems were often found but very little consultation took place between health and social services, indicating the need for better liaison between these services. The community child health clinics will need to be maintained if general practitioners cannot provide these services and are unable to include preventive as well as curative child care within their practice.

Since the introduction of the National Health Service general practice, community health services, and hospital services have developed separately. Although much has been achieved it is generally agreed that there is a need to develop an integrated health service for all children (Court and Jackson, 1972).

The Sheldon Report suggested in 1967 that the needs of children could best be met by the provision of a comprehensive primary care service based in general practice, combining curative and preventive care, and that general practitioners should therefore take over the services provided by local authority child welfare centres, later renamed 'child health clinics' (Ministry of Health, Central Health Services Council, 1967).

These recommendations have now been restated and amplified in the Court Report (1976). In order to develop such a service, it will be necessary in each health district to make an appraisal of the extent to which general practitioners have adopted these proposals. It will also be necessary to consider the current contribution of child health clinics in the care of children because the nature of the work of the clinics has changed as a result of the decline of infective illnesses and malnutrition, and an increasing interest in the developmental progress of children. The concept of developmental screening of the entire child population (Lancet, 1975) has also stimulated a change in emphasis from the traditional welfare activities of clinics, which consisted mainly in giving advice on feeding and on the day to day health problems of children, to the early detection of handicaps and their management. It has even been suggested that there is ${ }^{\circ}$. . . general recognition in the profession that the contribution of the clinics to the health service is not great ...' (Cartwright et al., 1975).

In addition, the recent separation of social from health services in the community as recommended in the Seebohm Report (1968) will need to be considered. It is widely believed that many problems have arisen as a result of this development and it will therefore be necessary to determine the nature and extent of these in order to develop an effective partnership for the care of all children.

\section{Methods}

A number of surveys of child health clinics were 
carried out during 1972-74 as part of a comprehensive study of hospital and community child care services in Newcastle upon Tyne (Steiner, 1975).

With the help of health visitors, a list was obtained of general practitioners who held a special child health clinic session for the children of the practice. Each clinic was visited in turn during 1973-74 and a record was made of the nature of the clinic, the reasons given by the mothers for visiting it, and the abnormalities and problems that were detected.

During a two-week period in March and again in June 1973, information was recorded for all children seen in community child health clinics by the medical officers and health visitors. This included the reasons for visiting the clinic, the frequency of previous visits, the problems that were detected, and whether the children were being seen by their own health visitor. (By that time all the health visitors in Newcastle were attached to general practitioners.)

During a one-year period from February 1972 to February 1973, observations were made weekly at a child health clinic. Information similar to that sought for the other surveys was recorded at each visit, and this included details of a standard developmental screening examination for each child. The clinic was situated in a poor area in the west end of Newcastle and it was anticipated that some families whose children were seen in the clinic would also avail themselves of the services of the nearby area social services department which was within 'prampushing' distance. Therefore on completion of the year's survey, information was sought from the records kept by the social services' team about the families who had also sought their advice during that time. In particular, an attempt was made to find out the reasons for seeking advice and the communications that had taken place between the child health clinic and the area social services.

The child health clinic surveys excluded children who attended only for immunisation during the regular monthly sessions held in the clinics for that purpose. They did, however, include children who were brought to the clinics for immunisation at other times.

\section{Results}

GENERAL PRACTITIONER CHILD HEALTH CLINICS

During 1973-74, only $12(11 \cdot 5 \%)$ out of 104 general practitioners had undertaken to hold a regular child health clinic in their practice. This involved nine $(19 \%)$ of the 47 practices in Newcastle and only four out of the 38 practices with less than four doctors in the practice (Table 1).
Table 1 General practitioner child health clinics in Newcastle, 1973-74

\begin{tabular}{lll}
\hline $\begin{array}{l}\text { No. of doctors in } \\
\text { the practice }\end{array}$ & Total & $\begin{array}{l}\text { No. with a regular } \\
\text { health clinic }\end{array}$ \\
\hline 1 & $17(36 \%)$ & 1 \\
2 & 11 & 1 \\
3 & 10 & 2 \\
4 & 6 & 4 \\
5 & 2 & 1 \\
6 & 1 & $-19 \%)$ \\
Total & 47 & $9 \quad(19 \%$ \\
\hline
\end{tabular}

Four out of nine clinics were intended only for children with medical complaints, four undertook health and birthday checks in addition to the management of children with medical problems, and one clinic was solely for health and birthday checks. A developmental screening examination was done in only two clinics and both doctors, unlike the other general practitioners, had worked in local authority child health clinics and had some experience in preventive child health. The majority, $58(54 \%)$ out of the 107 mothers in the survey sought advice about medical problems. These were respiratory tract infections (29), diarrhoea \pm vomiting (9), a rash (10), enuresis (2), inguinad hernia (2), and one each with headache, sore eyess a minor accident, bow legs, knock knees, and loss of weight. Some mothers sought advice about more than one problem. Twenty came for immunisation, 16 for a birthday check, eight came just to have the baby weighed and a health check, six sought advice about feeding difficulties, and four about a growth or developmental problem. The practice health visitor was always in attendance at the clinics but invariably the children were seen by the general practitioner. This differed from the community clinics in which the doctor saw only a few of the children and the health visitor spent most of her time talking to the mothers while the children were being weighed and advised them about feeding difficulties and other problems that did not require the attention of the doctor.

\section{COMMUNITY CHILD HEALTH CLINICS}

During a two-week period in June 1973, 1093 mothers visited the 42 community child health clinic sessions available in Newcastle. Of these, N $796(73 \%)$ saw the clinic health visitor only; the remainder, $297(27 \%)$ also consulted the clinic doctor. Only $223(20 \%)$ actually saw their own general practitioner attached health visitor. The majority had attended a community clinic in the past, often on numerous occasions-361 $(33 \%)$ on between one and five occasions, 444 (41\%) on between six and twenty occasions, and $165(15 \%)$ on more than 20 occasions. Only $123(11 \%)$ had 
never before been to a clinic.

The majority, $766(70 \%)$, were under the age of one year at the time of the visit, $162(15 \%)$ were aged between one and two years, and $165(15 \%)$ were over two years of age.

Most of the mothers $(77 \%)$ brought their children to be weighed and this provided an opportunity for the health visitor to give advice, support, and reassurance about the everyday problems of children and their families, such as the parents' adaptation to a new baby, feeding difficulties, and behaviour problems. Twenty-two per cent sought advice on feeding and only $16 \%$ had a specific medical complaint (Table 2).

Table 2 Reasons given to health visitors by 1093 mothers for visiting the community child health clinics in Newcastle June 1973

\begin{tabular}{lcc}
\hline Reason for visit & No. & $\%$ \\
\hline Weighing & 837 & 77 \\
Advice on feeding & 236 & 22 \\
Birthday check & 97 & 9 \\
Medical complaints & 176 & 16 \\
Immunisation & 154 & 14 \\
Growth and developmental problems & 96 & 9 \\
Family and social problems & 26 & 2 \\
To buy food and vitamins & 15 & $1 \cdot 4$ \\
To play in the clinic playgroup & 13 & 1 \\
Miscellaneous & 32 & 3 \\
\hline
\end{tabular}

More than one reason was sometimes given.

Only $297(27 \%)$ consulted the clinic doctor.

The reasons given by the 343 mothers for consulting the medical officers in the community clinics during a two-week period in March 1973 differed from those given by those visiting general practitioner clinics (Table 3). A large proportion came for a birthday or health check and others sought advice about feeding difficulties and growth and development problems. There were fewer medical complaints although these still comprised the main reason for consulting the child health clinic doctor.

Table 3 Comparison between reasons given by mothers for consulting community clinic doctors and general practitioners

\begin{tabular}{lll}
\hline & $\begin{array}{l}\text { Community } \\
\text { clinics } \\
\text { survey, } \\
\text { March } 1973 \\
(343\end{array}$ & $\begin{array}{l}\text { General } \\
\text { practitioners } \\
\text { survey } \\
1973-74 \\
\text { children) }\end{array}$ \\
$\begin{array}{lll}(107 \\
\text { children }) \\
\%\end{array}$ \\
\hline Birthday and health checks & 48 & 22 \\
Medical complaints & 41 & 54 \\
Immunisation & 13 & 21 \\
Feeding difficulties & 9 & 6 \\
Growth and developmental problems & 8 & 4 \\
Family and social problems & 4 & - \\
Miscellaneous* & $13 \cdot 5$ & - \\
\hline
\end{tabular}

*Includes hearing tests and medical examinations before day nursery

More than one reason for the risit was sometimes given.
The commonest problems identified by medical officers in the community clinics were medical conditions. In the survey carried out in a poor area of Newcastle social problems and significant maternal depression and anxiety were often noted (Table 4). It is noteworthy that in both of these surveys only a minority of children had a developmental problem (including speech) or a neurological abnormality.

Table 4 Problems identified by doctors in the community child health clinics

\begin{tabular}{|c|c|c|}
\hline & \multicolumn{2}{|c|}{ Newcastle surveys } \\
\hline & $\begin{array}{l}\text { All clinics, } \\
\text { March } 1973 \\
\text { (343 visits) }\end{array}$ & $\begin{array}{l}\text { One clinic in a } \\
\text { poor area, } \\
1972-73 \\
(242 \text { visits })\end{array}$ \\
\hline $\begin{array}{l}\text { Medical problems } \\
\text { Rash } \\
\text { Upper respiratory tract infection } \\
\text { Minor orthopaedic } \\
\text { Obesity } \\
\text { Failure to thrive } \\
\text { Miscellaneous } \\
\text { Feeding difficulties } \\
\text { Developmental delay } \\
\text { Speech problem } \\
\text { Squint } \\
\text { Maternal depression and anxiety } \\
\text { Social problem }\end{array}$ & $\begin{array}{r}111(32 \%) \\
42 \\
25 \\
14 \\
6 \\
4 \\
20 \\
32 \\
8 \\
8 \\
2 \\
7(2 \%) \\
7(2 \%)\end{array}$ & $\begin{array}{l}58(24 \%) \\
10 \\
29 \\
2 \\
\frac{1}{16} \\
31 \\
-4 \\
29(12 \%) \\
21(9 \%)\end{array}$ \\
\hline
\end{tabular}
year.

\section{BIRTHDAY CHECKS}

Eighty-two birthday checks were done during the survey of the work of the medical officers in the community child health clinics in March 1973. It was then the practice for the health visitors in Newcastle to arrange these examinations by inviting mothers to bring their children to the clinic, where a standard developmental screening examination was done by the clinic medical officer. No systematic attempts were made to cover the entire child population in Newcastle. It was found that most children examined had previously attended the clinic, often on numerous occasions-35 (43\%) more than 20 times, $24(29 \%)$ on between 11 and 20 occasions, and $19(23 \%)$ on between one and ten occasions; only four (5\%) had never been to a clinic before.

Thirty-three children were found to have some abnormality (Table 5), and they had all, except one child with a speech problem, attended clinics in the past. Children with the more serious, treatable abnormalities were already under hospital care and it is of particular interest that the diagnosis of developmental delay had already been made for the three children with this handicap. This was severe and obvious at a glance, and each had previously attended the clinic on 7,14 , and 19 occasions respectively. 
Table 5 Abnormalities detected during 82 birthday checks in the community child health clinics of Newcastle, March 1973

\begin{tabular}{|c|c|c|}
\hline Abnormality & No. & $\begin{array}{l}\text { No. already } \\
\text { attending } \\
\text { hospital }\end{array}$ \\
\hline $\begin{array}{l}\text { Minor orthopaedic } \\
\text { Rash } \\
\text { Upper respiratory tract infection } \\
\text { Delayed development } \\
\text { Speech problem } \\
\text { One each: }\end{array}$ & $\begin{array}{l}8^{*} \\
6 \\
5 \\
3 \\
3\end{array}$ & $\frac{1}{3}$ \\
\hline $\begin{array}{l}\text { squint } \dagger \text {, eczemat, epispadias } \dagger \text {, } \\
\text { strawberry naevust, obesity, } \\
\text { failure to thrive, undescended } \\
\text { testis, heart murmur }\end{array}$ & 8 & 4 \\
\hline
\end{tabular}

*Bow legs 3, knock knees 3, abnormalities of fingers 2.

†Already attending hospital.

AREA SOCIAL SERVICES

At the completion of the year's survey in a poor area in the west end of Newcastle, it was found that $44(28 \%)$ out of the 159 families whose children had been taken on 242 occasions to the community clinic had also visited the nearby area social services department. Seventeen $(11 \%)$ families had multiple problems requiring long-term social casework intervention, 13 sought help with clothing, seven had a housing problem, four had financial difficulties, one sought help in placing a child in a day nursery, one had a medical problem, and one had marital difficulties.

It is noteworthy that although a significant social problem had been identified in $14(9 \%)$ out of 159 at the time of a visit to the community child health clinic, consultations between community health and social services had taken place on only two occasions. Six of these families had subsequently been in contact with social services; five had multiple social problems and one had sought help in obtaining a cot and other household goods in anticipation of a new baby.

In seven families, there were indications that earlier and more effective social help could have been provided if prompt consultation had taken place between the clinic and the social services department after the mothers had visited the clinic.

\section{Discussion}

In Newcastle during 1973-74 only a few general practitioners had taken up the proposals of the Sheldon Report to provide child health clinic services, and yet it is clear that these services continued to be a popular and important part of child care services. The results of the survey point to some of the reasons for this failure to develop a comprehensive system of primary care within general practice. Most general practitioners were still working in small group practices, indeed 17 were singlehanded and only nine out of 47 practices comprised more than three doctors. It was often pointed out that it was difficult to allocate time and $\equiv$ resources to this work because of the pressure of $\stackrel{9}{+}$ more urgent work. There was a general lack of training and experience in preventive child health care and even among those who undertook this work, only two out of 12 had special experience as a result of having worked in local authority child health clinics. Even when a special session had been set aside for the children of the practice, this often consisted of an extra 'surgery' for children with relatively non-urgent minor illnesses, and only two clinics included any kind of developmental screening examination.

Other factors have probably contributed to the failure to develop this service in general practice. The contract of the general practitioner to provide 'general medical services' does not specifically include the provision of preventive child care and there may in some cases have been a lack of financial inducement to do this work. Many practices in Newcastle had patients scattered over a wide area which made it difficult, and sometimes costly, for mothers with young children to atten In contrast, community clinics were generally within 'pram-pushing' distance of their homes.

The popularity of community child health clinics with mothers was evident. It was estimated that approximately $60 \%$ to $70 \%$ of all mothers resident in Newcastle had taken their children to a clinic on at least one occasion during the first year of life 3 and many did so repeatedly. In addition to the accessibility of community clinics, it was clear that other factors played an important part in the continued popularity of the clinics. No appointment $\stackrel{\circ}{\rightarrow}$ was required (in contrast to the majority of general $\dot{0}$ practitioner clinics) and there was generally a more relaxed atmosphere with sufficient time to allow 8 mothers to talk about their children and their $₹$ problems. This was especially important in the clinic set in a poor area of the city where many mothers had significant personal and social problems which required time and patience to sort out. In contrast, general practitioner clinics were concerned o almost exclusively with medical complaints and $N$ curative care and generally did not make provision N for mothers with other problems.

It was clear that the community clinics still provided the traditional basic advisory and preventive child care services that were such a funda- $\stackrel{\infty}{+}$ mental feature of the work of the old "child welfare centres' (Sheldon Report, 1967). Only a limited amount of developmental screening (birthday $\mathbb{\mathbb { D }}$ checks) was done; few significant, previously

\section{,}


undetected abnormalities were found, mainly because the children so examined were generally those who had attended the clinics in the past. It seems appropriate, especially in the light of the current widespread interest in developmental screening which includes the screening of the entire child population, to draw attention to the danger of diverting interest and resources away from the continuing need to provide these basic services which, in a city like Newcastle, are still needed to supplement the services provided by general practitioners. This is particularly important at this stage of the development of child health services as it still has to be shown that developmental screening of all the children in the population is a practical, effective, and economical method of detecting all the significant treatable handicaps in children, especially in view of the complexities of the design and implementation of such a programme (Cartwright et al., 1975).

The community clinics were at a disadvantage because mothers were unlikely to see their own health visitors at the clinic. This was a direct result of the attachment of health visitors to general practices, many of which derived their patients from a wide area.

There was a considerable overlap between problems encountered in a community child health clinic located in a poor area of Newcastle and those encountered in a nearby social services department. It was clear that consultations and communications between these two services were inadequate and there was a strong feeling, shared by the social workers, that it would have been advantageous to have both health and social services in the same building.

\section{Conclusions}

The results that have been reported and the impressions that were formed in Newcastle during extensive contacts with general practitioners, health visitors, and social workers may not be applicable to other parts of the country. Nevertheless, it is suggested that it is essential to obtain this kind of information in order to plan an integrated child health service, and it may be that some of the lessons that have been learnt may have wider application.

In order to provide a comprehensive primary care service, it will be necessary for general practitioners to be adequately motivated and trained in preventive child care work. Group practices will need to be of adequate size, based in appropriate health centres, and should derive their patients from a clearly defined and appropriate geographical area to enable families to make the best use of the service and health visitors to provide the most effective care.

If general practitioners are unable to take up this work, it will be necessary to maintain the community child health clinics which continue to provide such an important and popular service.

Finally, there is a need to establish an effective professional partnership between health and social services. This will require a greater understanding of the role of each service and could be facilitated by the provision of both services within the same building and by the attachment of social workers to general practices.

I am grateful to the Nuffield Provincial Hospitals Trust for its support and to the many general practitioners, health visitors, social workers, and other colleagues who helped me to see their patients and records and who freely discussed their problems with me.

Reprints from H. Steiner, MD, MRCP, Senior Lecturer in Child Health, University of Newcastle, Newcastle upon Tyne NE1 7RU.

\section{References}

Cartwright, K., Down, J., Snaith, A. H., and Trickey, A. J. (1975). Design and implementation of a developmental paediatric screening programme. In Bridging in Health. Published for the Provincial Hospitals Trust by the Oxford University Press: London.

Court Report (1976). Fit for the Future (Report of the Committee on Child Health Services). HMSO: London.

Court, D., and Jackson, A. Editors (1972). Paediatrics in the Seventies. Published for the Provincial Hospitals Trust by the Oxford University Press: London.

Lancet (1975). Leading article. Developmental screening. Lancet, 1, 784-786.

Ministry of Health, Central Health Services Council (1967). Sheldon Report (Report of the Subcommittee of the standing Medical Advisory Committee Child Welfare Centres). HMSO: London.

Seebohm Report (1968). Report of the Committee on Local Authority and Allied Personal Social Services. HMSO: London.

Steiner, H. (1975). Paediatrics in hospital and community in Newcastle upon Tyne. In Bridging in Health. Published for the Provincial Hospitals Trust by the Oxford University Press: London. 